\title{
Gender Disparity and Discrimination in the Field of STEM
}

\author{
Xiaoyu Chen ${ }^{1, \dagger}$, Yike $\operatorname{Liu}^{2, \dagger}$, Yixin $\mathrm{Luo}^{3, \mathrm{a},{ }^{*}, \dagger}$, Siying Wang ${ }^{4, \dagger}$, Zhiyue Zhu ${ }^{5, \dagger}$ \\ ${ }^{1}$ Maple Leafe International school, Shanghai, China \\ ${ }^{2}$ Zhengzhou Foreign Language School, Zhengzhou, China \\ ${ }^{3}$ College of Arts and Sciences, Social Sciences Interdisciplinary, University at Buffalo, Buffalo, United States \\ ${ }^{4}$ Rectory School, Pomfret, United States \\ ${ }^{5}$ School of Economics and Management, Business Administration, Shanghai Ocean University, Shanghai, China \\ ${ }^{*}$ Corresponding author. Email: ${ }^{a}$ yixinluo@buffalo.edu \\ These authors contributed equally.
}

\begin{abstract}
This paper focuses on finding different investigations linked to the issue of gender disparities and discrimination of women in STEM to examine the reasons and remedies for gender differences in STEM. This literature study also displays basic information about STEM to provide individuals a solid grasp of this area and a series of data and explanations that show the gender disparities in this domain. At the end of this literature, some suggestions for reducing gender gaps in STEM fields are offered to motivate individuals to take action. It is minimizing gender inequalities and eliminating gender discrimination in STEM-related fields.
\end{abstract}

Keywords: Gender disparity, Gender discrimination, STEM

\section{INTRODUCTION}

The STEM (Science, Technology, Engineering, and Mathematics) field is extremely significant for developing the world industry. In terms of genders, women have the same capability, talent, and potential as men studying and working in the STEM industry. STEM is more suited to males, who have long been stereotyped in the minds of others. Women see STEM as a long road filled with hurdles and stumbling blocks. The advancement of the female population in the STEM sector is hampered by gender. Soft thinking, such as literature or history, is a good fit for girls. This prejudice is driven by the long-held belief that caused lower employment for females in the STEM fields. Males are thought to be more skilled in technical areas and to surpass women in spatial analysis. Such unfavorable perceptions may inadvertently lead people to believe that men are better suited to learning and working in STEM subjects.

Furthermore, before delving deeper into the present state of gender imbalance in STEM education, readers must clearly grasp the importance of STEM education. STEM education has become a powerful economic driver in both emerging and developed countries, such as
Europe and the United States. Women indeed face more challenges in earning a degree in science, technology, engineering, or mathematics (STEM). Gender inequality and prejudice grew in the professional area of STEM, notably among women faculty, and even impacted the female-dominated field of study in science. Because male characteristics are perceived as more valuable and a better match for playing a leading role, people with stereotypically male traits such as competitiveness or independence are more likely to be promoted to a leadership position in the STEM field than people with stereotypically feminine characteristics such as nurturing. When it comes to gender imbalance, it is a major issue that is closely linked to education and society throughout the world. Instead of thinking that males are better capable of studying STEM or anything else, women should grow their confidence while investigating themselves. The most important thing we can do is do our hardest to eliminate or reduce gender discrimination in STEM and other professions. This literature review emphasized discovering the gender disparities and discrimination against the female community in the field of Science, Technology, Engineering, and Mathematics, regarding explanations of disparities and associated solutions to disparities and discrimination. 


\section{DEVELOPMENT OF GENDER STEREOTYPES IN STEM}

STEM is more suitable for the males that became a stereotype in former people's mindsets. Women approach the STEM field as a long journey full of challenges and obstacles [1]. Nevertheless, women are still creating miracles for this particular field of study and research. Marie Curie (2011) was a famous scientist of many firsts; she was the first woman to win a Nobel Prize and the first person to win the Nobel Prize two times. The first prize was the Nobel Prize in Physics in 1903, and the other was the Chemistry Prize in 1911 [2]. It is just one of many outstanding women who contributed to STEM research and earned a place in the STEM field. The achievements (1903) of Marie Curie is a great beginning to encourage women to be involved in STEM, but it does not indicate that women have a satisfactory prospect in this field. Women's participation in STEM fields has not grown to a level commensurate with their activities in society. This kind of non-growing, even regressing situation forms from the STEM gap. Only 30 percent of women worldwide study in the STEM field (in information technology, the percentage drops to only three percent; decreases to eight percent in engineering) [1]. Approximately four out of ten (44\%) people who work in STEM explained why the number of women working in STEM is significantly fewer is due to the lack of encouragement in STEM-related subjects for girls in their early years. Both men (43\%) and women (45\%) tend to agree on this particular explanation [3]. In general, gender (refers to the social concepts of male and female) limits the development of the female community in the STEM field.

However, social conditions change at any time. Women gradually entered into the STEM field in the last 40 years. Eng (2018) compared women related to the STEM field between 1978 and 1989 to those entering 2008 and 2017 to explore the difference between the two decades. Through the analysis "Industries That Have Seen the Most Change in Female Representation," more women enter STEM than any other field. Although more and more women have been recruited into traditionally male leading industries, such as architecture or agriculture (In people's stereotypes, architecture, agriculture, and scientific subjects are not suitable occupations for women. These three fields require intellectual workers and manual laborers. People have already accepted more males who work in these fields. In that case, the public can hardly accept women working in these fields. In other words, women are appropriate in the STEM field while people can't accept it.). However, females still serve as operating posts dominated by women, such as marketing and human resources. The ability of females improved quickly, although modernday inequality still existed between males and females. For example, female leaders enjoy high salaries in the
United States, although women still earn fewer salaries than men. Discrimination has existed between males and females. Therefore, decreasing the gender gap between males and females is the only thing we can do [4].

Girls are suited to soft thinking such as literature or history. A long-standing idea influences this kind of stereotype; females are often in the state of being vacant in the STEM field. However, this stereotype is not just a verbal statement without guarantee. The reason for the gender imbalance in STEM is due to the influence of external factors. According to the research from the United States, girls tend to lose confidence in STEM studies because they believe the males are cleverer in the aspects of technique and outperform women in the spatial analysis [5]. Sometimes such negative stereotypes may cause people to be involuntary in thinking that male is more suitable in learning and working in the STEM fields.

\section{EXPLANATIONS OF GENDER DISPARITIES AND DISCRIMINATION IN STEM}

Before going further about the current situation of gender disparity in STEM education, readers must have a clear understanding of the great significance of STEM education. STEM education has become an economic catalyst in both developing countries and longestablished countries like Europe and the United States. The developed countries are having an increasing demand for more qualified researchers and technicians. Gender disparities in the field of higher education within the STEM majors or courses have indicated some forms of inequality and biases in terms of academics and engagement. According to the research "Beneath the numbers: A review of gender disparities in undergraduate education across science, technology, engineering, and math disciplines," there is a systematic bias in college education among male and female students. Researchers had found that the average GPA (Grade Point Average) among females is higher than the males before they attended colleges or universities. It indicates that female students are more likely to obtain higher GPAs than male students in higher education under the same condition. Nevertheless, studies have presented that male students seemed to have better performance than female students. Such phenomena might result from the lower participation and engagement of female students because female students often feel uncomfortable answering questions in front of the whole class compared with males [6]. Besides, the study demonstrated that in the STEM field, where the gender ratio favors males over females, female students have relatively lower self-efficacy and a lower sense of belonging than males in classroom settings. In other words, females feel less accepted as a member of the community of STEM [6]. These phenomena are highly associated with the socio-cultural factor of gender stereotypes and gendered socialization that negatively impacted the female population. 
Women are indeed having more difficulties graduating with a degree in science, technology, engineering, or math (STEM) fields [7]. Taking a closer look at the statistics, it is not difficult to find out that although women predominate the medical and health science degrees and jobs in recent years, they are still under-represented in most STEM fields. According to the research, $42.5 \%$ of women continued finishing Bachelor's courses in STEM among university sophomores, compared with $58.2 \%$ of men in the same age group [8]. Statistics on earned Bachelor's Degrees in 2012 show that women were awarded $59 \%$ of degrees in biology but made up only $43 \%$ in mathematics and statistics, $19 \%$ of degrees in engineering, and $38 \%$ of degrees in the physical and technological sciences [9]. The problem that should be emphasized here is that the gender gap in the STEM field is an extremely common phenomenon worldwide, both in developing countries and the developed countries. The chart of the "Percent Females among All Universities Graduates and in Engineering and Science" presents eight countries (all of them are developed countries) in which women make up the majority of college students (except Italy). However, females take up less than half of the graduates in science or engineering. For students who do not sign up for a STEM program, in the beginning, it is indeed difficult for them to graduate with a STEM degree due to the obstacles of transferring. Therefore, we can simply understand that "taking entry to university in a STEM program is a proximate endpoint for understanding the gender gap in STEM [7]." The factors that cause such disproportional situation can be demonstrated by six current empirically supported explanations for the gender gap in STEM: (a) "cognitive ability," (b) "relative cognitive strengths," (c) "career preferences," (d) "lifestyle values," (e) "field-specific ability beliefs, and (f) "gender-related stereotypes and bias" [9].

The first term, "Cognitive ability," plays a role as the first explanation in illustrating the gender gap in STEM. In Wang and Degol's research study (2017), even though the average math grades for girls outperform boys; on the contrary, the results of high-stakes standardized assessments indicated higher scores for boys than girls. Nevertheless, recent meta-analyses provided evidence that the gender differences of math ability depended on standardized assessments are too nuanced to be countable due to the diminutive average effect size $(\mathrm{d}<0.15)$ based on samples, testing source, grade level, and the year of the research [9]. Some of the "cognitive abilities" of gender differences (such as spatial relations tasks) that tend to be male-advanced have been diminished by utilizing time constraints and cross-national differences in gender equality [9]. Beyond the average difference of standardized assessments among males and females, extending research discovered an incommensurately higher number of males in the extreme right percentile of the distribution, which contributed to various intelligent
STEM professionals. Suppose the underrepresentation of females in math-intensive fields can be primarily explained by cognitive ability. In that case, it is reasonable to expect the ratio of male-to-female employees in STEM as such proportions of 4:1 [9].

Another evidence justified that distinctions in absolute cognitive ability do not present the differences between genders in STEM. Instead, gender differences can be explained by the differences in the breadth of cognitive ability; in other words, "relative cognitive strengths" are more persuasive in expounding the gender differences in terms of career choices in STEM [9]. In Wang and Degol's study, they mentioned that talented people have a higher possibility to have uneven ability profiles than the average population, which may impact decision-making in choosing a career. Wang's study revealed a strong prediction of potential career choices regarding math and verbal performance among mathematically gifted people. Those individuals with higher math skills than verbal skills are more likely to engage in STEM careers, while individuals with relatively equal math and verbal skills tend to engage in the non-STEM fields. These ability patterns can be divided by genders, in which females have a higher possibility than males to be both mathematically and verbally skilled. In that case, females' abilities may not be the priority compared to their interests and values. It explains why mathematically gifted females tend to pursue more practical and applied non-STEM careers due to "relative cognitive strengths" [9].

"Career preference" is another factor that may contribute to the underrepresentation of females in STEM fields. A meta-analysis presented that males prefer working with objects, while females have a preference for working with others. Men were discovered to have greater interests in STEM. Women tend to engage in careers in socially oriented occupations, which may be driven by altruism because women are more willing to help other people and benefit society [8]. Even women who work in the STEM field have a higher possibility of pursuing careers that focus on community or are peopleoriented, which actively demonstrates that career preferences may serve higher priority than the ability [9].

"Lifestyle preferences," as the fourth factor for explaining the gender gap in STEM, illustrated priorities males and females place on career and family. Men are not as willing as women to make sacrifices in their careers for their families, but men have higher rates of preferring work-centered lifestyles compared with female counterparts [9]. When considering making fertility plans, there is a conflict between optimal years and career pursuits in STEM fields for women, which is unsuitable for achieving females' familial goals. Thus, the proportion of full-time occupations of female employees are relatively lower than male employees. As women become parents, those with children will tend to 
prioritize family-centered goals over other values [9]. The possibility that females will give up their careers is very high, especially for mothers. Nearly half of the females who worked in STEM in the U.S. stop working after caring for their children [1].

"Field-specific ability" beliefs potentially explain the gender gap in STEM. Research suggests people tend to consider male-dominated fields require innate intelligence (which was believed to be impactful for success in careers) compared with women-dominated fields; such results are applicable regardless of whether in STEM or non-STEM fields. People with a fixed mindset believe intelligence is static, while people with a growth mindset believe intelligence can be shaped by practicing and putting efforts at a persisting pace [9]. For some girls with a fixed mindset in believing math ability is an innate intelligence, it could be problematic for these girls to solve a challenging math problem or have a satisfying performance than boys. These findings indicate that females may avoid engaging in STEM careers because having fixed mindsets of STEM requires innate intelligence and hold the wrong perspective that they may not belong to this community which requires such qualities [9].

As the last factor contributing to explaining the gender gap in STEM, "gender-related stereotypes and biases" are controversial in the extent of causing the underrepresentation of females in math-intensive careers. It is controversial because previous research had failed to find any persuasive pattern of discrimination against females in pursuing careers in STEM fields. Thus, a conclusion was drawn that discrimination and prejudice against women in STEM is historical causation, instead of current causation that leads to the underrepresentation of female employees [9]. Two forms of discrimination have been identified. They can be distinguished by overt or intentional forms of gender discrimination and covert or subtle forms of gender discrimination, including the behaviors of denying the existence of discrimination, hostility to women demanding equality, and dissatisfaction with special privileges given to women to promote equality. Besides, hostile (including the ideas and behaviors of derogatory and exploitation toward women) and benevolent (including the ideas and behaviors of affection toward women) forms of sexism have been distinguished by the research; both forms of sexism include the belief in subordinating women to men. These two forms play roles in keeping men in the position of power and maintaining the patriarchy in a steady place [9]. Although it is less prevalent to witness deliberate practice of discrimination, covert and benevolent forms are still omnipresent throughout the lifespan, which will undoubtedly mould the career trajectories of both males and females. Parents and teachers often underestimate girls' math ability. They frequently attribute boys' math success more to capability and math failure than lack of effort while having the opposite attitude to girls [9]. The discriminatory behaviors are more likely to occur as young men and women begin to explore their career interests, and peers may become significant influences in exploring future careers. Young people under the encouragement of peers in pursuing STEM majors are more likely to participate and have higher motivation in STEM courses. Such finding applies to both boys and girls, but there is a slightly stronger association between peer relationships and girls' math and science beliefs. In other words, due to pervasive gender stereotypes in STEM, girls in these fields may be more socially influenced by their peers, which can be detrimental if peers do not support girls' math/science interests [8]. Gender stereotypes and implicit biases indeed affect women's selection and interest in STEM fields or prevent them from developing their skills in these fields; therefore, male-dominated fields of study or careers will remain "male-dominated" [9].

The gender gap in the STEM field not only exists in universities. This research of Wang and Degol also analysed the differences between two genders from the different periods regarding "biological perspective," "sociocultural explanations," and the "Family-Work balance" perspective. These mixed factors brought more obstacles for females to work in such intense STEM fields [9]. Therefore, it is answerable to having fewer women working in STEM areas than male employees. Nevertheless, the number of women in STEM careers has increased, particularly in recent years. The proportion of the women population working in STEM was nearly $35 \%$ higher in 2017 than in 2003. Although the proportion of women working in the STEM area has significantly increased, the women who worked in STEM careers still remain a minority regarding gender. In the United States, the proportion of women-only occupies $28 \%$ of the overall science and engineering and $60 \%$ of the social science workforce [10].

In the professional field of STEM, particularly in women faculties, gender disparity and discrimination further developed and even impacted the femaledominated field of study in science. In the professional field of STEM, people with stereotypically masculine characteristics such as competitiveness or independence are more favorable than people with feminine characteristics such as nurturing in promoting to a leadership position, because masculine characteristics are perceived as more valuable and a better match in playing a leading role [11]. The study also demonstrated that female faculties' general academic and working environment is unwelcoming, threatening, and hostile. Women faculties often reported feeling more uncomfortable and harassed, less satisfaction and productivity in their working places. Thus, female faculties often experience discrimination and have relatively limited promoting opportunities than male faculties [11]. The level of education also determines the degree to which women are discriminated against in 
STEM careers. More educated women are more likely than their less-educated counterparts in STEM to report workplace discrimination and recognize that gender was an essential barrier to success [3].

\section{SOLUTIONS TO GENDER DISPARITIES AND DISCRIMINATION IN STEM}

Speaking of gender disparity, it is a significant issue that is strongly correlated to education and society worldwide. Women should develop their confidence while exploring themselves, instead of thinking that men are more capable of studying STEM or something else. The most crucial aspect we could contribute is to try our best to solve or decrease gender discrimination in STEM and other fields. For example, in high school, teachers should make attempts to ensure female students can reach the same standard of STEM education as other male students. Also, educators should cultivate female students' interest in the STEM field and encourage girls to pursue non-traditional career paths instead of traditional ones. For instance, many girls are encouraged to become teachers or accountants as a future career to meet social expectations of gender roles. However, if they are encouraged to access the STEM field, they can choose to become a mathematician, scientist, or someone else with a career that is usually not considered a job for females.

Furthermore, in math class or science class, teachers should make both girls and boys involved in class and ensure that all of the students have the same opportunities and receive proper feedback. Both girls and boys should be expected highly in class [12]. Several solution proposals can also be determined at the end of the article written by Wang and Degol, such as offering more career options for women, enhancing women's interests in science subjects, reducing masculine stereotypes, and so on. In the end, Wang and Degol mentioned that it is essential for policymakers, practitioners (taking action), and researchers (providing empirical support) to collaborate [9] to reduce gender disparities and discrimination. Society must be more generous and more inclusive regarding both men's and women's academic or professional choices, instead of limiting their decision by long-held conservative beliefs. Gender disparity might have a reason to exist, but discrimination, stereotypes, and bias shouldn't be the ideal results of gender disparity.

Though women are being discriminated against in STEM, many facts indicate that women with STEM degrees earn more than those who hold non-STEM degrees. At the same time, as for men, the same case occurs here in which men with STEM-related degrees earn higher salaries. Besides, the largest STEM-related wage premiums belong to men and women who both major in a STEM field and choose a STEM job, which helps us eliminate the concern. As a matter of fact, women with a STEM degree who pursue their jobs in the
STEM fields can earn more than the women at the same age who neither have STEM degrees nor occupy their jobs in the STEM field [13]. Therefore, we can recognize the advantage of women studying STEM and obtaining a job in STEM. Nevertheless, female undergraduates earn lower salaries than male undergraduates in STEM. Although in the 1980s, the earnings for female college graduates have grown in line with those of all college graduates. Some of the differences in salary are associated with gender. For example, the salary gap between males and females was 30.1 percent in STEM fields in Australia [10].

To sum up, in the classroom settings, what educators can do to help eliminate gender discrimination is to take steps to ensure that both girls and boys are treated fairly in every circumstance, and the confidence of girls in studying in a STEM field should be cultivated so that girls won't be afraid to explore these non-traditional subjects. In addition, positive development of gender disparity should fill in gaps in the STEM field and other fields instead of favoring men over women. However, the public should also realize what advantages STEM brings to women, such as higher wages among other peers who do not engage in the STEM field. Women may be willing to receive STEM education and STEM employment and be concerned about the comments given by stereotypes; for instance, many people believe women cannot study STEM. To eliminate such discrimination, the public should change the general environment gradually and be less strict with women's choices.

\section{CONCLUSION}

Until today, although females share the same rights as males in pursuing an education or career in the field of STEM, and the population of women entering the STEM industry has been increasing each year. Females are still being marginalized in a male-dominated realm as minorities and are likely to encounter more challenges than males due to the long-term stereotypes and biases that are deeply rooted in people's minds towards this particular community. Six evidence-based explanations can justify the disparities of genders in STEM. Those internal and external factors make working and studying in an intense STEM field even more challenging for women to balance their lives and careers. Faculties play an active role in reducing gender disparities and biases between males and females students with several listed solutions above. In that case, female students will be able to increase their confidence in exploring the nontraditional field of study or career. People hold negative beliefs for females to engage. Gender disparities may have reasons to exist; with that being said, gender discrimination and stereotypes should be eliminated because they might cause negative impacts to the socialcultural development in not only STEM but also other fields of studies. 


\section{REFERENCES}

[1] Gallego BBVA. (n.d.). Women and STEM field: a long journey full of hard obstacles. NEWS BBVA. https://www.bbva.com/en/opinion/women-andstem-a-journey-full-of-obstacles/

[2] Ishak, N. (2019, August 12). The Impeccable Brilliance Of Marie Curie, One Of History's Greatest Scientists. All That's Interesting; All That's Interesting. https://allthatsinteresting.com/marie-curie

[3] Funk, C., \& Parker, K. (2021). Women in STEM see more gender disparities at work, especially those in computer jobs, majority-male workplaces. https://www.pewresearch.org/socialtrends/2018/01/09/women-in-stem-see-moregender-disparities-at-work-especially-those-incomputer-jobs-majority-male-workplaces/

[4] Mejia, Z. (2018b, March 7). More women entered STEM over the past 40 years than any other field, new data shows. CNBC. https://www.cnbc.com/2018/03/07/more-womenentered-stem-over-the-past-40-years-than-anyother-field.html

[5] Sorby, S. A. (2009). Educational research in developing 3-D spatial skills for engineering students. International Journal of Science Education. $\quad 31 \quad$ (3): $\quad 459-80$. https://www.tandfonline.com/doi/full/10.1080/095 00690802595839

[6] Eddy, S., \& Brownell, S. (2016, August 1). Beneath the numbers: A review of gender disparities in undergraduate education across science, technology, engineering, and math disciplines. Physical Review. Physics Education Research, 12(2), 020106-. https://doi.org/10.1103/PhysRevPhysEducRes.12.0 20106

[7] Card, D., \& Payne, A. A. (2021). High school choices and the gender gap in STEM. Economic Inquiry, 59(1), 9-28. https://onlinelibrary.wiley.com/doi/epdf/10.1111/ec in. 12934

[8] Gender gaps in STEM college majors emerge in high school. (n.d.). Cornell Chronicle. https://news.cornell.edu/stories/2020/07/gendergaps-stem-college-majors-emerge-high-school

[9] Wang, M. T., \& Degol, J. L. (2017). Gender Gap in Science, Technology, Engineering, and Mathematics (STEM): Current Knowledge, Implications for Practice, Policy, and Future Directions. Educational psychology review, 29(1),
119-140. https://doi.org/10.1007/s10648-0159355-X

[10] Bradbury, P. (2015). What is the current state of play, what are the key issues and why does it matter? http://www.professionalsaustralia.org.au/profession al-women/wpcontent/uploads/sites/48/2014/03/WOMEN_IN_ST EM_v2.pdf

[11] Casad, B., Franks, J., Garasky, C., Kittleman, M., Roesler, A., Hall, D., \& Petzel, Z. (2021). Gender inequality in academia: Problems and solutions for women faculty in STEM. Journal of Neuroscience Research, 99(1), 13-23. https://doi.org/10.1002/jnr.24631

[12] Farinde, A. A., \& Lewis, C. W. (2012). The underrepresentation of African American female students in STEM fields: Implications for classroom teachers. Online Submission. https://files.eric.ed.gov/fulltext/ED533550.pdf

[13] Beede, D. N., Julian, T. A., Langdon, D., McKittrick, G., Khan, B., \& Doms, M. E. (2011). Women in STEM: A gender gap to innovation. Economics and Statistics Administration Issue Brief, (04-11). https://eric.ed.gov/?id=ED523766 